\title{
5 Research Square

\section{Prevalence of myopia in primary and middle school pupils and its influencing factors in Keerqin District: Logistic regression analysis}

\section{Huiying Zhuang}

Inner Mongolia University for the Nationalities

\section{Limei Wang}

Centers for Disease Control and Prevention

\section{Fengying Wang}

Centers for Disease Control and Prevention

\section{Geisi Tang}

Inner Mongolia University for the Nationalities

\section{Tianzi Zhang}

Affiliated Hospital of Inner Mongolia University for Nationalities

Honglin Zhao ( $\nabla$ zhaohonglin0475@163.com )

Inner Mongolia University for the Nationalities

\section{Research Article}

Keywords: Primary and middle school pupils, myopia, prevalence rate, influencing factors

Posted Date: March 8th, 2022

DOI: https://doi.org/10.21203/rs.3.rs-1363836/v1

License: (1) This work is licensed under a Creative Commons Attribution 4.0 International License.

Read Full License 


\section{Abstract}

\section{Introduction: Purpose:}

We evaluated the prevalence of myopia and its relationship with associated factors in primary and middle school pupils in Keerqin District of Tongliao City.

\section{Methods}

Measurement data on poor eyesight and ametropia from 1757 senior grade students in primary, junior middle, and high school, as well as electronic questionnaires were analyzed by stratified random cluster sampling in November 2020. Myopia was indicated by a visual acuity of $<5.0$ and a refractive error (spherical equivalency) of $<-0.50$ refractive (D) in each eye. Chi-square and binary logistic regression analyses were used to identify the potential risk factors for myopia.

\section{Results}

The overall prevalence of myopia was $64.31 \%$, with the rate of wearing glasses being $49.29 \%$. Increasing grade was associated with a significant increase in the prevalence of myopia among female, Hans and residential school pupils. Children whose parents were myopic were highly found to be myopic. When reading, the rate of myopia in which eyes were never $>1$ feet from books was higher. It was also established that parents occasionally or never reminded their children that reading and writing postures have a low risk of nearsightedness. Close eyes use, $0.25-0.5 \mathrm{~h}$ eye rest reduced the risk of myopia development.

\section{Conclusion}

The overall prevalence of myopia was high, indicating that myopia is a serious public health concern in Keerqin District of Tongliao City. However, the rate of eyeglass wearing was relatively low. Myopia was positively correlated with education level, female gender, residential schools, genetics and the environment.

\section{Introduction}

The prevalence of myopia among young children in China is high. Myopia damages the physical as well as mental health of young children, affects the scope of their future career choices, and causes a heavy economic burden on the society. Poor eyesight is the main cause of visual impairments. High myopia causes various blinding complications, such as cataracts, glaucoma, retinal detachment, and myopic maculopathy [1]. The World Health Organization's first world eyesight report (released on October 8th, 2019) revealed that globally, >2.2 billion people suffer from visual impairments or blindness [2]. By 2050, 
the global number of myopic patients is expected to reach 4.758 billion people ( $49.8 \%$ of the total population) [3]. East Asian countries like China, Singapore and South Korea have high myopia rates, exceeding the rates in Europe and the United States. Globally, China has the highest rate of myopia, with its prevalence being highest in young people $[4,5]$. The technical guide for the prevention and control of myopia in children and adolescents developed by the National Health Commission in 2019 recommends that schools, families, and communities work together to reduce long-term persistent myopia in children and adolescents [6]. In children, myopia is associated with various environmental factors, such as socioeconomic factors, nearby work, and outdoor activities [7]. Close work activities such as studying, reading, watching TV, and computer work are environmental risk factors for myopia. A high outdoor time prevents the development of myopia and reduces the risk of nearsightedness that is associated with close work or myopic parents [8]. A Chinese study involving 15316 pupils with an average age of $12.1 \pm 3.3$ years from 18 areas of Beijing found that sleep deprivation is an independent risk factor for myopia. Incidences of eye diseases have also increased sharply due to continuous growth in digital media consumption [9]. A recent study reported that about 60 years ago, only $10 \%$ of the Chinese were nearsighted, but in 2015 , over $90 \%$ of teenagers were myopic [10]. Long-term use of smartphones plays an important role in visual impairments and increases the likelihood of poor eyesight $[11,12]$.

We investigated the prevalence of myopia and the factors associated with its occurrence among primary and middle school pupils of Keerqin District, Tongliao city. Elucidation of environmental and lifestyle factors that contribute to myopia progression is essential for providing a reference for formulation of ample prevention as well as control strategies and measures for primary and middle school pupils' myopia.

\section{Methods}

\section{Research design and participants}

According to the circular of the Ministry of Education and other eight departments on issuance of the implementation plan for comprehensive prevention and control of myopia in children and adolescents, the survey began on May, 2020, and ended on December, 2020. This survey was conducted by stratified random cluster sampling from November 2020 to December 2020. First, stratified sampling was used to select 2 primary schools, 2 junior middle schools, and 2 high schools. Stratified cluster sampling was then used to randomly select 2 classes in each grade of each school. Due to poor coordination of examinations of lower grade pupils in primary schools, only senior grade, primary school pupils were included in this study (4-6 grade). Pupils who were willing to cooperate with various examinations and questionnaires were included in this study. A total of 1757 primary and middle school pupils were investigated. Effective recovery rate of questionnaires was $100 \%$. The study group comprised 903 boys (51.3\%), 854 girls (48.7\%), 465 Han pupils (26.5\%), 1164 Mongolian pupils (66.2\%), 128 pupils of other nationalities (7.3\%), 823 resident in school pupils (48.8\%), and 934 non-resident in school pupils (51.2\%). There were 587 senior grade of primary school pupils (33.3\%), 620 junior high school pupils (35.3\%), and 550 high school pupils (31.4\%). 


\section{Ophthalmological examination}

Pupils were examined in classrooms in November 2020. The main visual examination was divided into distant eyesight examination and refractive test and was done by at least one ophthalmologist holding an optometry-related national qualification certificate assisted by optometry technicians. Normal eyesight for children of different ages is as follows: 3 -years old: $4.8,4$ years old: $4.9,5$ years old: $>5.0$ [13]. Since the pupils involved in this study were all aged 5 years and above, uncorrected eyesight of $<5.0$ was considered poor. Refractive test under noncycloplegic autorefraction was used to diagnose myopia. All ametropia readings were recorded as equivalent spherical degrees of the eye so as to reduce the number of false positive myopic results [14].

\section{The definition of myopia}

Myopia is indicated by a naked visual acuity of $<5.0$ and an equivalent computer optometry diopter of $<-0.5$ (D) under noncycloplegic. This definition was selected to minimize false positive myopia and is consistent with the definition used in previous studies. Based on a naked visual acuity of $<5.0$ in each eye, participants were divided into 3 ametropic groups with regards to spherical equivalent refraction (SER): low myopia (<-0.5D to >-3.0D), moderate myopia ( $\leq-3.0 \mathrm{D}$ to $>-6.0 \mathrm{D})$, and high myopia ( $\leq 6.0 \mathrm{D})$ $[15,16]$.

\section{Questionnaire survey}

The questionnaire used in this study was self-designed to suit our aims and it mainly included the potential risk factors related to eyesight, including basic information (grade, gender, whether living in school, nationality), genetic factors (parents' myopia), and environmental factors like in-school eye environment, out-of-school eye use, reading and writing posture, electronic screen use, close-up eye use, outdoor activities, parents' conditions, and myopia examination. Electronic questionnaires were distributed by members of the monitoring staff through the student common diseases and health influencing factors monitoring and input system platform. Then, they were filled out by parents and pupils and reviewed the next day. In case of problems, pupils were asked to make changes or provide supplements. Pupils who were unable to fill in the questionnaires were allowed to contact their parents for guidance. In cases where the questionnaires were complete or corrected, students' data were destroyed.

\section{Quality control}

Recruitment by study staff began in May 2021 and continued through December 2021. Prior to the start of the study, the research team was trained on the purpose, method, and process of investigation. A pilot test was conducted to improve the language, logic, and question sequence on the questionnaire. Project members distributed all the questionnaires and gave detailed instructions on how to fill them out during field data collection. The health department examined the professional institutions entering the school, 
strengthened the on-site quality control, and selected $5 \%$ of the pupils for on-site review. Incomplete questionnaires were not submitted.

\section{Statistical analysis}

All data were entered into spreadsheets by school health professionals, sorted and analyzed by SPSS 25.0. The adoption rate or constituent ratio of counting data was described. The $\chi 2$ test was used for inter-group comparisons. $p \leq 0.05$ indicated significant differences. The Bonferroni method was used for multiple comparisons. Nominal test level was 3 groups of comparison $a^{\prime}=0.0166 . p \leq 0.0166$ indicated significant differences. Binary logistic regression was used to analyze the factors influencing myopia. First, univariate analysis was performed to evaluate potential associations. Then, Binary logistic regression modeling was performed to analyze all statistically significant factors found in the univariate analysis. Odds ratios (OR) and the corresponding $95 \%$ confidence interval $(\mathrm{Cl})$ were calculated to identify myopia risk factors. In the model, $\mathrm{OR}>1.0$ and $p<0.05$ indicated that a parameter was a risk factor, while $\mathrm{OR}<1.0$ and $p<0.05$ indicated that a parameter was a protective factor. $p \leq 0.05$ indicated significant differences.

\section{Results}

Eyesights and glass wearing rates among students at different learning stages are shown in Table 1 . The rates of poor vision and myopia were $68.47 \%$ (1203/1757) and 64.31\% (1130/1757), respectively. Myopia rates in the senior grade of primary school, junior middle school, and high school, were $49.67 \%(291 / 587)$, $77.58 \%(481 / 620)$ and $65.09 \%$ (358/550), respectively. The total rate of wearing glasses by myopic students was $49.29 \%(557 / 1130)$.

Table 1

Eyesight and eyeglass wearing by pupils at different learning stages in Keerqin District, Tongliao city.

\begin{tabular}{|llllllll|}
\hline $\begin{array}{l}\text { Learning } \\
\text { stage }\end{array}$ & Number & $\begin{array}{l}\text { Poor } \\
\text { eyesight }\end{array}$ & $\begin{array}{l}\text { Detection } \\
\text { rate of poor } \\
\text { eyesight(\%) }\end{array}$ & Myopia & $\begin{array}{l}\text { Detection } \\
\text { rate of } \\
\text { myopia(\%) }\end{array}$ & $\begin{array}{l}\text { Myopia } \\
\text { glass } \\
\text { wearing }\end{array}$ & $\begin{array}{l}\text { The rate } \\
\text { of wearing } \\
\text { glasses in } \\
\text { myopia(\%) }\end{array}$ \\
\hline $\begin{array}{l}\text { Senior } \\
\text { grade of } \\
\text { primary } \\
\text { school }\end{array}$ & 587 & 325 & 55.36 & 291 & 49.57 & 113 & 38.83 \\
\hline $\begin{array}{l}\text { Junior } \\
\text { middle } \\
\text { school }\end{array}$ & 620 & 497 & 80.16 & 481 & 77.58 & 332 & 69.02 \\
\hline $\begin{array}{l}\text { high school } \\
\text { Total }\end{array}$ & 550 & 381 & 69.27 & 358 & 65.09 & 112 & 31.28 \\
\hline
\end{tabular}

Table 2: The prevalences of mild myopia in high school and junior middle school were lower than in senior grade of primary schools. However, the prevalence of moderate myopia and high myopia in high 
school and junior middle school were higher than those in the senior grade of primary schools. The prevalence of moderate myopia in high school were higher than in junior middle school, however, the prevalence of high myopia was lower than in junior middle school $(p<0.001)$. The prevalences of moderate and high myopia were high in girls than in boys, however, the prevalence of mild myopia was low in girls than in boys $(p<0.001)$. The prevalence of moderate myopia in Mongolians was lower than in Hans $(p=0.02)$. The prevalence of high myopia in non-residential schools was lower than in residential schools $(p=0.03)$. The prevalence of mild myopia in pupils whose parents were not myopic was higher than for those with myopic parents, but the prevalences of moderate and high myopia were significantly low than in those with myopic parents $(p<0.001)$. 
Table 2

Types and related demographic factors of myopia among primary and middle school pupils in Keerqin District of Tongliao City.

\begin{tabular}{|c|c|c|c|c|c|c|}
\hline \multirow[t]{2}{*}{ Variable } & \multirow{2}{*}{$\begin{array}{l}\text { Normal } \\
\text { eyesight }\end{array}$} & \multicolumn{3}{|c|}{ Degree of myopia } & \multirow{2}{*}{$\chi^{2}$} & \multirow{2}{*}{$\begin{array}{l}\mathrm{P} \text { - } \\
\text { value }\end{array}$} \\
\hline & & Mild & Moderate & Severe & & \\
\hline \multicolumn{2}{|l|}{ Grade } & & & & 73.33 & $\begin{array}{l}<.001 \\
0.00\end{array}$ \\
\hline $\begin{array}{l}\text { Senior grade of } \\
\text { primary school }\end{array}$ & $342(45.17)$ & $256(61.53)$ & 131(31.49) & $28(6.98)$ & & \\
\hline $\begin{array}{l}\text { Junior middle } \\
\text { school }\end{array}$ & $135(22.80)$ & $208(45.41)^{\mathrm{a}}$ & $183(39.95)^{\mathrm{a}}$ & $66(14.64)^{a}$ & & \\
\hline high school & $146(37.24)$ & $\begin{array}{l}107(43.49) \\
b\end{array}$ & $107(43.49)^{b c}$ & $32(13.02)^{b c}$ & & \\
\hline \multicolumn{2}{|l|}{ Gender } & & & & 30.78 & $\begin{array}{l}<.001 \\
0.0\end{array}$ \\
\hline Male & $379(41.97)$ & $288(54.96)$ & 182(34.73) & $54(10.31)$ & & \\
\hline Female & $250(29.27)$ & $295(49.00)^{\star}$ & $234(38.74)$ * & $75(12.26)$ * & & \\
\hline \multicolumn{2}{|l|}{ Ethnic group } & & & & 4.95 & 0.02 \\
\hline Hans & 153(32.90) & 153(49.04) & $125(40.06)$ & $34(10.90)$ & & \\
\hline Mongolias & $450(38.66)$ & $368(51.52)$ & $263(36.83)^{+}$ & $83(11.65)$ & & \\
\hline \multicolumn{2}{|l|}{$\begin{array}{l}\text { Whether or not to } \\
\text { live on campus }\end{array}$} & & & & 4.72 & 0.03 \\
\hline Yes & $282(34.30)$ & $260(48.14)$ & $210(38.88)$ & $70(12.98)$ & & \\
\hline No & $344(36.83)$ & $323(54.74)$ & 209(35.42) & $58(9.84)^{\#}$ & & \\
\hline \multicolumn{2}{|l|}{$\begin{array}{l}\text { Parents are } \\
\text { nearsighted }\end{array}$} & & & & 31.99 & ¿. 001 \\
\hline Yes & $130(25.64)$ & 155(41.11) & $156(41.37)$ & $66(17.52)$ & & \\
\hline No & 499(39.92) & $421(56.05)^{\Delta}$ & $270(35.95)^{\Delta}$ & $60(8.00)^{\Delta}$ & & \\
\hline \multicolumn{7}{|c|}{$\begin{array}{l}\text { Grade: }{ }^{a} p<0.01 v s \text { senior grade of primary school, }{ }^{b} p<0.01 \text { vs senior grade of primary school, }{ }^{c} p<0.01 \mathrm{vs} \\
\text { junior middle school. Gender } \rrbracket^{\star} p<0.01 \mathrm{vs} \text { male. Ethnic group } \rrbracket+p<0.05 \text { vs Han. Campus resident vs } \\
\text { campus non-resident: }{ }^{\#} p<0.05 \text { vs campus resident. Parents are nearsighted: }{ }^{\Delta} p<0.01 \text { vs parents not } \\
\text { nearsighted. }\end{array}$} \\
\hline
\end{tabular}

Figure 1: School eye environment (class seat exchange, desk and chair height adjustment with height, and recess activity location) influenced myopia $(p<0.05)$. The number of daily eye exercises at school did not affect myopia. Eye use outside school (age of participating in extracurricular classes and daily 
homework/reading time) influenced myopia $(p<0.05)$. Parents' restriction of children's time on electronic products, time of attending cram school daily and whether parents reduced exercise time in order to study did not affect myopia. Reading and writing postures (whether parents reminded pupils of their reading and writing postures, whether the chest was more than one punch from the edge of the table, and whether the eyes were more than one foot from the book) influenced myopia $(p<0.05)$. Whether the finger was an inch from the tip of the pen, and whether the teacher reminded students about reading and writing postures did not affect myopia. Eye shutting, (close eyes use, and how often eyes rested, eyes being $>3$ meters from the TV screen, eyes being $>66 \mathrm{~cm}$ from the computer screen, reading books or electronic screens while walking or taking the bus, turning off the lights to look at the electronic screen after dark) affected myopia $(p<0.05)$. Lying or lying on the stomach, reading or electronic screens, reading in direct sunlight or electronic screens, type of reading lamp and writing after dark had no effect on myopia. Electronic screen usage (in the past week, time spent watching TV daily, and time spent using mobile electronic devices daily) had an impact on myopia $(p<0.05)$. In the previous week, time spent watching the computer daily did not affect myopia. The time spent on outdoor activities in a week had no effect on myopia. The number of myopia examinations in one year had an impact on myopia $(p<0.05)$.

Table 3 shows that that myopia risk increased with increasing grade. Myopia in junior middle school $\left(\mathrm{OR}_{1}=4.567,95 \% \mathrm{Cl}=3.366-6.197\right)$ and high school $\left(\mathrm{OR}_{2}=3.532,95 \% \mathrm{Cl}=2.380-5.241\right)$ were higher than in the senior grade of primary school. Myopia prevalence was highest in junior middle school. The risk of myopia was higher in girls than in boys $(\mathrm{OR}=1.651,95 \% \mathrm{Cl}=1.333-2.045)$. Myopia risk for residential school pupils was higher than for non-residential school pupils $(\mathrm{OR}=0.648,95 \% \mathrm{Cl}=0.469-$ $0.895)$. Additionally, adolescents whose either parent had myopia $(\mathrm{OR}=1.865,95 \% \mathrm{Cl}=1.424-2.442)$ or both parents were myopic $(\mathrm{OR}=3.101,95 \% \mathrm{Cl}=1.809-5.316)$ had a high myopia risk, relative to those whose parents did not have myopia. Adolescents whose parents were both myopic had the highest risk of myopia. The risk of myopia was high when reading with eyes not more than 1 foot from the book (OR = $1.822,95 \% \mathrm{Cl}=1.033-3.213)$, relative to reading with eyes more than 1 foot from the book. Parents occasionally $(\mathrm{OR}=0.617,95 \% \mathrm{Cl}=0.440-0.846)$ or never $(\mathrm{OR}=0.634,95 \% \mathrm{Cl}=0.429-0.938)$ reminded their children that reading and writing postures can protect from adolescent myopia. However, they always reminded their children that reading and writing postures are risk factors for adolescent myopia. Close eye rest for $0.25-0.5 \mathrm{~h}$ reduced the risk of myopia $(\mathrm{OR}=0.610,95 \% \mathrm{Cl}=0.389-0.956)$. 
Table 3

Logistic regression analysis of influencing factors of myopia among primary and middle school pupils in Keerqin District of Tongliao City.

\begin{tabular}{|c|c|c|c|c|}
\hline \multirow[t]{2}{*}{ Influencing factors } & \multirow[t]{2}{*}{$\begin{array}{l}\mathrm{P}- \\
\text { value }\end{array}$} & \multirow[t]{2}{*}{ OR } & \multicolumn{2}{|c|}{$\begin{array}{l}95 \% \text { confidence } \\
\text { interval }\end{array}$} \\
\hline & & & $\begin{array}{l}\text { Lower } \\
\text { limit }\end{array}$ & $\begin{array}{l}\text { Upper } \\
\text { limit }\end{array}$ \\
\hline \multicolumn{5}{|l|}{ Grade } \\
\hline senior grade of primary school & & 1.000 & & \\
\hline junior middle school & 0.000 & 4.567 & 3.366 & 6.197 \\
\hline high school & 0.000 & 3.532 & 2.380 & 5.241 \\
\hline \multicolumn{5}{|l|}{ Gender } \\
\hline male & & 1.000 & & \\
\hline female & 0.000 & 1.651 & 1.333 & 2.045 \\
\hline \multicolumn{5}{|l|}{ Living conditions on campus } \\
\hline resident in the school & & 1.000 & & \\
\hline non-residents in the school & 0.008 & 0.648 & 0.469 & 0.895 \\
\hline \multicolumn{5}{|l|}{ Myopia of parents } \\
\hline neither parent is nearsighted. & & 1.000 & & \\
\hline one parent is myopic. & 0.000 & 1.865 & 1.424 & 2.442 \\
\hline both parents are myopic & 0.000 & 3.101 & 1.809 & 5.316 \\
\hline \multicolumn{5}{|c|}{ Whether the eyes were more than one foot from the book } \\
\hline always & & 1.000 & & \\
\hline often & 0.451 & 1.180 & 0.767 & 1.817 \\
\hline occasional & 0.102 & 1.448 & 0.929 & 2.256 \\
\hline never & 0.038 & 1.822 & 1.033 & 3.213 \\
\hline \multicolumn{5}{|c|}{$\begin{array}{l}\text { Whether parents reminded pupils of their reading and } \\
\text { writing posture }\end{array}$} \\
\hline always & & 1.000 & & \\
\hline often & 0.420 & 0.887 & 0.662 & 1.188 \\
\hline occasional & 0.003 & 0.617 & 0.449 & 0.846 \\
\hline never & 0.023 & 0.634 & 0.429 & 0.938 \\
\hline
\end{tabular}




\begin{tabular}{|lllll|}
\hline Influencing factors & $\begin{array}{l}\text { P- } \\
\text { value }\end{array}$ & OR & \multicolumn{2}{l|}{$\begin{array}{l}\text { 95\% confidence } \\
\text { interval }\end{array}$} \\
\cline { 4 - 6 } & & & $\begin{array}{l}\text { Lower } \\
\text { limit }\end{array}$ & $\begin{array}{c}\text { Upper } \\
\text { limit }\end{array}$ \\
\hline Close eyes use, and how often eye rest is taken(h) & & & & \\
\hline$<0.25$ & & 1.000 & & \\
\hline $0.25 \sim$ & 0.031 & 0.610 & 0.389 & 0.956 \\
\hline $0.5 \sim$ & 0.090 & 0.676 & 0.429 & 1.063 \\
\hline $1 \sim$ & 0.310 & 0.794 & 0.509 & 1.240 \\
\hline $2 \sim$ & 0.732 & 0.922 & 0.579 & 1.468 \\
\hline$\geq 3$ & 0.864 & 0.950 & 0.528 & 1.709 \\
\hline
\end{tabular}

\section{Discussion}

This is the first study of the prevalence of myopia and related factors in primary and middle school pupils in Keerqin District, Tongliao City, inner Mongolia. In this study, myopia was assessed by noncycloplegic autorefraction (SER < - 0.50 D). This method ensures high participation, because participation in studies is entirely voluntary and most parents do not want to give their children cycloplegia. We selected a group of voluntary students for cycloplegic autorefraction and no difference non-cycloplegic autorefraction.

The total prevalence of myopia among primary and middle school pupils was $64.21 \%$, which was higher than reported for other areas. The prevalence of myopia among primary and middle school pupils in eastern China was 49.50\% [17] while in Tibet, it was 23.80\% [18]. However, this rate was lower than reported in Japan (84.90\%) [19], but similar to the rate reported in South Korea (64.6\%) [20]. Thus, myopia is an important public health problem in primary and middle school pupils in Keerqin District of Tongliao city. The total rate of wearing glasses for primary and middle school pupils in Keerqin District of Tongliao City was $49.29 \%$, which was similar to that of Chengdu (48.07\%) [21], and slightly higher than in Jiangsu province (34.56\%) [22]. The reasons underlying low spectacle wearing outcomes among myopic individuals might be multifactorial, including a lack of screening for detecting myopia, teasing or bullying by peers, low attention and consciousness for the need of glasses, or mis-conception by parents or students that wearing glasses will worsen myopia $[23,24,25]$. Thus, educating students and parents on the importance of timely screening for myopia and wearing glasses for best vision is very important.

The risk of myopia in junior and high schools was higher than in senior grades of primary schools. Pan $\mathrm{CW}$ et al. reported that higher grades are associated with higher rates of high myopia [26]. This could be because education systems increase study time and decrease outdoor activity time, which are important risk factors for myopia [27, 28]. Additionally, high myopia is more common in junior high schools. Thus, 
prevention/intervention strategies are needed to prevent myopia, since high myopia increases the risk of eye diseases and loss of eyesight.

There are gender-associated differences in myopia prevalence [29, 30], with girls having a 1.651 higher risk of myopia. In this study, girls had higher rates of mild myopia, moderate myopia, and severe myopia, consistent with findings from other parts of China, such as Guangzhou [29] and Xichang [30]. An Indian study found that girls living in urban areas are more likely to be myopic than boys [31]. This may be because girls spend more time studying and less time participating in outdoor activities than boys. Therefore, to enhance myopia prevention and control, girls should be key targets.

Tongliao city is the main residence for Mongolians, with a large number of Mongolian primary and middle school pupils living in Keerqin district. The prevalence of moderate myopia among Mongolian primary and middle school pupils was lower than that of pupils of the Han nationality, consistent with a school-based cross-sectional study conducted in Turpan. The prevalence of myopia is lowest among Uygur minorities (13\%) and highest among Hans (27\%) [32]. Similar observations were made in a Yunnan study, which showed the prevalence of myopia among Hans to be $71.7 \%$, and that in children of ethnic minorities to be $35.7 \%$ [33]. This could be because Mongolians and Hans occupy different living environments while their eating habits and genetic factors also vary. The prevalence of severe myopia in residential primary school and middle school pupils were higher than in non-residential schools. Binary logistic regression revealed that the risk of myopia in the non-residential school was lower than in residential schools, probably due to a lack of parental control when pupils live at school. This may allow pupils to stay up late to play video games or use mobile phones under poor lighting. These findings have not been discussed in other Chinese studies.

Parental myopia is a genetic risk factor for myopia in children [29, 34]. Saw SM et al. confirmed that parents' myopia is an important risk factor for children's myopia [35]. There are significant correlations between parental and child myopia. Relative to non-myopic parents, one- and two-parent myopia increases the risk of myopia in adolescence by 1.865 and 3.101 times, respectively. Children whose 2 parents have nearsightedness exhibit a higher risk of myopia than children with non-myopic parents [36]. Olavi Pärssinen and Markku Kauppinen found that for Chinese children with an average age of 11.45, the prevalence of myopia in children with 1 or 2 myopic parents was 2-3 times higher than that of children without myopic parents [37]. In Poland, if both parents are myopic, the OR of children with high myopia in adulthood has been shown to be 3.9 [38]. In this study, the prevalence of mild myopia, moderate myopia, and severe myopia were high for children with myopic parents, relative to those without myopic parents.

Close work is an important risk factor for myopia, such as reading, writing, and working on a computer. Sherwi et al. reported that children who read from less than 30 centimeters have a 2.5 times higher incidence of myopia, relative to those with longer reading distances. Additionally, children who read for > $30 \mathrm{~min}$ at a time exhibited higher incidences of myopia, compared to those who read for $<30 \mathrm{~min}$ [39]. The risk of myopia for those who never read at a distance of more than a foot from a book was 1.822 times higher, relative to those who always read from more than a foot away. Additionally, a break for 
$0.25-0.5 \mathrm{~h}$ at a time was associated with the lowest risk of myopia. As the impact of close reading on the onset and progress of myopia has been shown to be high, it is necessary for primary and secondary school pupils to avoid spending unnecessary time on close-up activities. Moreover, these activities should be performed under strict supervision by parents.

We found that parents reminding their children to pay attention to their reading and writing postures too frequently increases their risk of myopia, while occasionally reminding or no reminding at all reduces children's risk of myopia. The reason that some children got more reminders from their parents might be that they had more bad eye habits, which may contribute to higher risks of myopia.

The overall prevalence of myopia in this study was relatively high, indicating that myopia was a serious public health problem in Keerqin district of Tongliao city, while the rate of eyeglass wearing was relatively low. Myopia was positively correlated with increasing grade, female gender, residence in school, parents' myopia, close reading, frequent reminders by parents about children's reading and writing postures and < $0.25 \mathrm{~h}$ eye rest. Due to the high rates of myopia, it is necessary for all sectors of the society to act together to improve parents and schools' attention to pupils' eyesight and psychological development. Additionally, pupils' academic burdens should be reduced and bad eye habits corrected. Diet should also be reasonably matched.

\section{Declarations}

\section{Ethical statement}

Ethics approval and Consent to Participate

This study was approved by the Institutional Review Board at Inner Mongolia University for the Nationalities, A20200501, and was carried out in adherence to the tenets of the Declaration of Helsinki. Study participants were anonymized and any identifiable personal information were not collected. Prior to being enrolled in this study, every participant was informed of and understood the purpose of our investigation. Written informed consent forms were obtained from the children's parents before the eye examinations and questionnaires.

\section{Funding}

This study was financially supported by a grant from the National Natural Science Foundation of China (81960831).

\section{Availability of data and materials}

All data generated or analysed during this study are included in this published article [and its supplementary information files].

\section{Acknowledgments}


The authors thank all adolescent and their families for participating in this study. Thanks are due to all the participants for their efforts and time. We also thank Joe Barber Jr, PhD of Liwen Bianji (Edanz) company (www.liwenbianji.cn/) for editing the English writing of this manuscript.

\section{Authors' contributions}

HYZ, LMW, FYW, GST, TZZ conceived and planned this study and take full responsibility for the paper. HYZ took the lead in writing the manuscript. HLZ supervised this study and contributed to revision of the paper. All authors read and approved the final manuscript.

\section{Competing interests}

The authors declare that they have no competing interests.

\section{Consent for publication}

Not applicable.

\section{References}

1. COOPEXJQTKATCHENKOAV. A review of current concepts of the etiology and treatment of myopia. Eye Contact Lens. 2018,44(4):231-247.PubMed

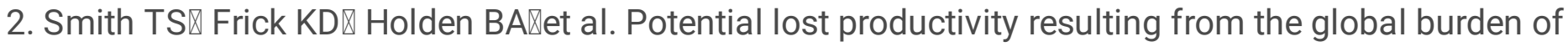
uncorrected refractive error. Bull World Health Organ. 2009,87:431-437.PubMed

3. Holden BA, Fricke TR, Wilson DA, et al. Global prevalence of myopia and high myopia and temporal trends from 2000 through 2050. Ophthalmology. 2016,123(5):1036-1042.PubMed

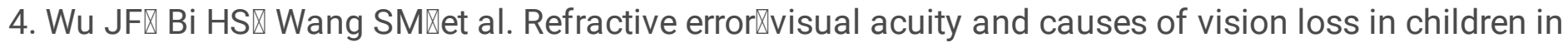

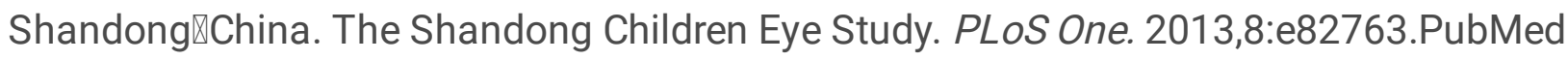

5. Ding BY $\triangle$ Shih YF区 Lin LLK囚 et al. Myopia among schoolchildren in East Asia and Singapore. Surv Ophthalmol. 2017,62:677-697.PubMed

6. Sherwin $\mathrm{JC} \otimes$ Reacher $\mathrm{MH} \otimes \mathrm{Keogh} \mathrm{RH} \otimes$ et al. The association between time spent outdoors and myopia in children and adolescents: a systematic review and meta-analysis. Ophthalmology. 2012,119:2141-2151.PubMed

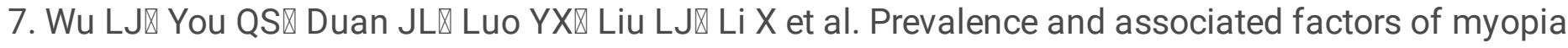
in high-school pupils in Beijing. PLoS One. 2015,10(3):e0120764.www.CNKI.net

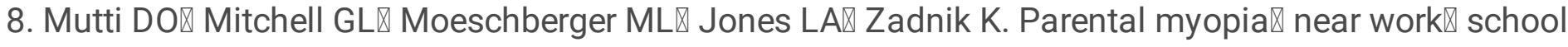

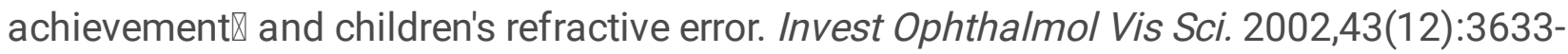
3640.PubMed

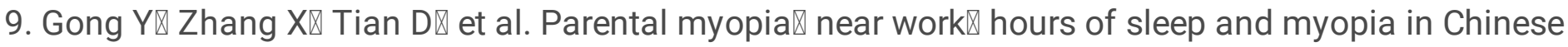
children. Health. 2014,06:64-70.

10. Dolgin E. The myopia boom. Nature. 2015,519(7543):276-278.www.CNKI.cn 


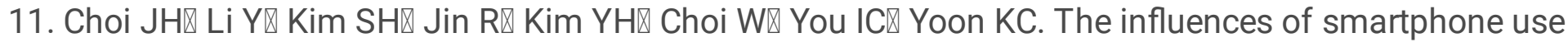
on the status of the tear film and ocular surface. PLoS One. 2018,13(10):e0206541.PubMed

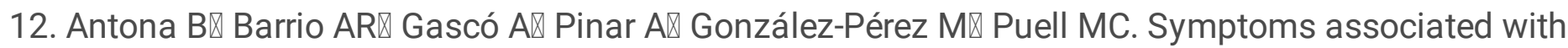
reading from a smartphone in conditions of light and dark. Appl Ergon. 2018,68:12-17.PubMed

13. Wang Lihua, Chen Wei, Feng Jingjing, et al. Analysis of refractive state of 674 children with low vision at the age of 3 to 6 years. Chinese Journal of Optometry and Visual Science. 2017,19 (3):168171.wWw.CNKI.cn

14. Hashemi H, Rezvan F, Ostadimoghaddam H, Abdollahi M, Hashemi M, Khabazkhoob M. High prevalence of refractive errors in a rural population: 'Nooravaran Salamat' Mobile eye clinic experience. Clin Exp Ophthalmol. 2013,41(7):635-643.PubMed

15. Mirshahi A, Ponto KA, Hoehn R, Zwiener I, Zeller T, Lackner K et al. Myopia and level of education: results from the Gutenberg Health Study. Ophthalmology. 2014,121(10):2047-2052.PubMed

16. Saxena R, Vashist P, Tandon R, Pandey RM, Bhardawaj A, Menon V et al. Prevalence of myopia and its risk factors in urban school children in Delhi: the North India Myopia Study (NIM Study). PLoS One. 2015,10(2):e0117349.PubMed

17. F. ,orn, J. Chen, C. Li et al. Refractive status and prevalence of myopia among Chinese primary school pupils. Clinical and Experimental Optometry. 2020,103(2):177-183.PubMed

18. X. Qian, B. Liu, J. Wang et al. Prevalence of refractive errors in Tibetan adolescents. BMC Ophthalmology. 2018,18(1):118.PubMed

19. E. Yotsukura, H. Torii, M. Inokuchi et al. Current prevalence of myopia and association of myopia with environmental factors among schoolchildren in Japan. JAMA Ophthalmology. 2019,137:12331239.PubMed

20. D. H. Lim, J. Han, T.-Y. Chung, S. Kang, and H. W. Yim, The high prevalence of myopia in Korean children with influence of parental refractive errors: the 2008-2012 Korean National Health and Nutrition Examination Survey. PLoS One. 2018,13(11):e0207690.PubMed

21. Liu Linglin, Wu Zhengzheng, Li Dongfeng, et al. Analysis of prevalence and influencing factors of myopia among adolescents in Chengdu and Mianyang. International Journal of Ophthalmology. 2019,19 (7):1196-1200.www.CNKI.cn

22. Zhang Peibin, Wei civilian, Su Lixin, et al. Investigation on myopia wearing glasses and eye hygiene among primary and middle school students in Jiangsu province. Chinese Journal of Child Health. 2014,22 (7):752-754.www.CNKI.cn

23. Wang X, Yi H, Lu L, et al. Population prevalence of need for spectacles and spectacle ownership among urban migrant children in eastern China. JAMA Ophthalmol. 2015,133(12):1399-1406.

24. Congdon N, Zheng M, Sharma A, et al. Prevalence and determinants of spectacle nonwear among rural Chinese secondary schoolchildren: the Xichang pediatric refractive error study report 3 . Arch Ophthalmol. 2008,126(12):1717-1723.

25. Morjaria P, Evans J, Gilbert C. Predictors of spectacle Wear and reasons for nonwear in students randomized to ready-made or custom-made spectacles: results of secondary objectives from a 
randomized noninferiority trial. JAMA Ophthalmol. 2019,137(4):408-414.

26. Pan CW, Wu RK, Li J, Zhong H. Low prevalence of myopia among school children in rural China. BMC Ophthalmol. 2018,18(1):140.PubMed

27. He M, Xiang F, Zeng $Y$, et al. Effect of time spent outdoors at school on the development of myopia among children in China: a randomized clinical trial. JAMA. 2015,314(11):1142-1148.PubMed

28. Wu PC, Tsai CL, Wu HL, Yang YH, Kuo HK. Outdoor activity during class recess reduces myopia onset and progression in school children. Ophthalmology. 2013,120(5):1080-1085.PubMed

29. Guo L, Yang J, Mai J, Du X, Guo Y, Li P, et al. Prevalence and associated factors of myopia among primary and middle school-aged pupils: a school-based study in Guangzhou. Eye (Lond). 2016,30(6):796-804.PubMed

30. Lu B, Congdon N, Liu X, Choi K, Lam DS, Zhang M, et al. Associations between near work, outdoor activity, and myopia among adolescent pupils in rural China: the Xichang pediatric refractive error study report no. 2. Arch Ophthalmol. 2009,127(6):769-775.PubMed

31. S. Sheeladevi, B. Seelam, P. Nukella, R. Borah, R. Ali, and L. Keay. Prevalence of refractive errors, uncorrected refractive error, and presbyopia in adults in India: a systematic review. Indian Journal of Ophthalmology. 2019,67:583-592.PubMed

32. Chin MP, Siong KH, Chan KH, Do CW, Chan HHL, Cheong AMY. Prevalence of visual impairment and refractive errors among different ethnic groups in schoolchildren in Turpan, China. Ophthalmic and Physiological Optics. 2015,35(3):263-270.PubMed

33. Yang YJ, Chang LT, Lyu H. Epidemic status and influencing factors for the poor eyesight of the pupils in Yunnan. Chin J Sch Health. 2015:36:12.www.CNKI.cn

34. Guo Y, Liu LJ, Xu L, Lv YY, Tang P, Feng Y, et al. Outdoor activity and myopia among primary students in rural and urban regions of Beijing. Ophthalmology. 2013,120(2):277-283.www.CNKI.cn

35. Saw SM, Shankar A, Tan SB, Taylor H, Tan DT, Stone RA, et al. A cohort study of incident myopia in Singaporean children. Invest Ophthalmo/ Vis Sci. 2006,47(5):1839-1844.PubMed

36. Zhang X, Qu X, Zhou X. Association between parental myopia and the risk of myopia in a child. Exp Ther Med. 2015,9(6):2420-2428.PubMed

37. O. P"arssinen and M. Kauppinen, Risk factors for high myopia: a 22-year follow-up study from childhood to adulthood. Acta Ophthalmologica. 2019,97:510-518.PubMed

38. X. Wu, G. Gao, J. Jin et al. Housing type and myopia: the mediating role of parental myopia. BMC Ophthalmology. 2016,16(1)-151.PubMed

39. Sherwin J. C., Reacher M. H., Keogh R. H., Khawaja A. P., Mackey D. A., Foster P. J. The association between time spent outdoors and myopia in children and adolescents. Ophthalmology. 2012,119(10):2141-2151.PubMed

\section{Figures}



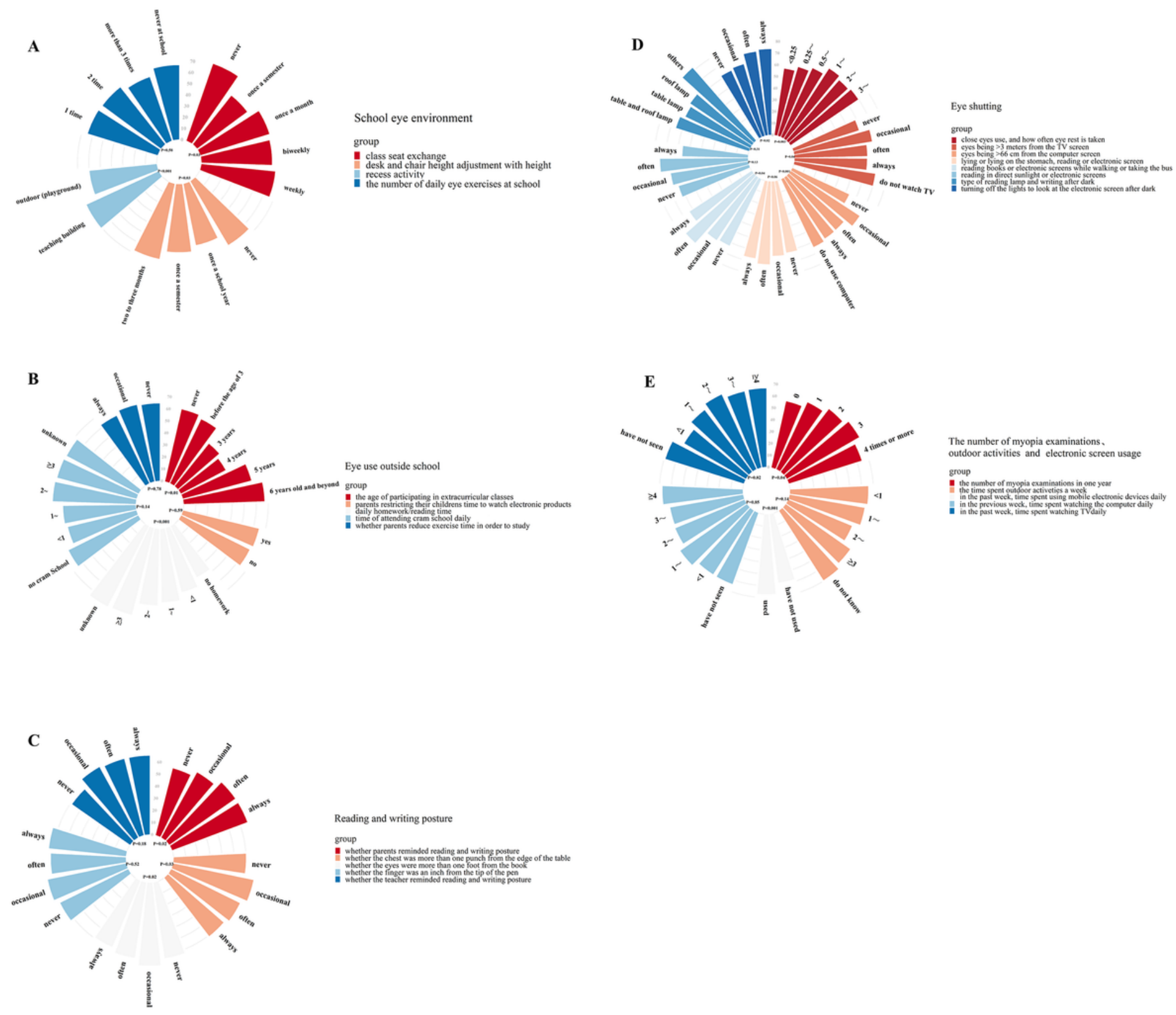

\section{Figure 1}

Single factor analysis of influencing factors of myopia among primary and middle school pupils in Keerqin District of Tongliao City.

(A):School eye environment. (B):Eye use outside school. (C):Reading and writing posture. (D):Eye shutting. (E): The number of myopia examinations $\square$ outdoor activities and electronic screen usage.

\section{Supplementary Files}

This is a list of supplementary files associated with this preprint. Click to download. 
- data.xIsx

Page 17/17 